Editor's Note: These short reviews of a recent paper in the Journal, written exclusively by graduate students or postdoctoral fellows, are intended to mimic the journal clubs that exist in your own departments or institutions. For more information on the format and purpose of the Journal Club, please see http://www.jneurosci.org/misc/ifa_features.shtml.

\title{
Hunting for Synaptic Tagging and Capture in Memory Formation
}

\author{
José Viosca, Dragana Jancic, José P. López-Atalaya, and Eva Benito \\ Instituto de Neurociencias de Alicante, Universidad Miguel Hernández-Consejo Superior de Investigaciones Científicas, Campus de Sant Joan, 03350 \\ Alicante, Spain \\ Review of Moncada and Viola (http://www.jneurosci.org/cgi/content/full/27/28/7476)
}

Long-term potentiation (LTP) and some forms of long-term memory share a number of properties, such as associativity, durability, and protein synthesis dependence. These similarities suggest that LTP could be the cellular substrate for memory (Bliss and Collingridge, 1993). The recently reported changes in synaptic transmission caused by learning in behaving animals (Gruart et al., 2006; Whitlock et al., 2006) have provided significant support to this view and attracted attention to additional properties of LTP potentially relevant in memory formation. Ten years ago, Frey and Morris (1997, 1998) performed a series of two-pathway stimulation experiments that led them to propose the synaptic tagging and capture hypothesis. In their seminal work, Frey and Morris $(1997,1998)$ showed that early-LTP, a transient form of LTP, which is induced by a weak stimulus, could be converted into late-LTP, a more persistent form of LTP, if the weak and the strong stimuli were applied temporally close to each

Received Sept. 6, 2007; revised 0ct. 2, 2007; accepted 0ct. 2, 2007.

This work was supported by grants from Generalitat Valenciana BFPI06/ 316 (J.V.), Eusko Jaurlaritza BFI06.30 (E.B.), European Commission MEXT(T-2003-509550 (D.J.), and Fundación la Marató TV3 063510 (J.P.L.A.). We thank Angel Barco, Mikel Lopez de Armentia, Luis Miguel Valor, and Eloisa Herrera for critical reading of and helpful comments about this manuscript.

Correspondence should be addressed to José Viosca, Instituto de Neurociencias de Alicante, Universidad Miguel Hernández-Consejo Superior de Investigaciones Científicas, Campus de Sant Joan, Apartment 18, Sant Joan d'Alacant, 03350 Alicante, Spain. E-mail: jviosca@umh.es.

DOI:10.1523/JNEUROSCI.4093-07.2007

Copyright $\odot 2007$ Society for Neuroscience $\quad$ 0270-6474/07/2712761-03\$15.00/0 other on different synapses of the same neuron. These results suggested an interaction between the molecular events connecting early- and late-LTP in different pathways. Thus, the authors speculated that such a mechanism might explain why inconsequential events are remembered for much longer if they occur around the same time as relevant well remembered events. A decade later, a recent study by Moncada and Viola (2007) in The Journal of Neuroscience tested the validity of this prediction in vivo.

By combining two behavioral tasks, Moncada and Viola (2007) investigated whether a behavioral experience could extend the duration of the memory for an independent task and whether this interaction displayed properties consistent with synaptic capture. In the inhibitory avoidance paradigm (IA), a hippocampaldependent task (Whitlock et al., 2006), rodents receive an electrical foot shock immediately after they step down from a platform, so they suppress the step-down behavior the next time they are placed on the platform. Thus, the step-down latency can be used as a parameter to assess memory retention. To answer the question of whether this memory could be promoted by its coincidence with an independent task, the authors combined this paradigm with the exploration of a novel spatial context (an open field), which also activates neurons in area CA1 (Vianna et al., 2000). They showed that weak training in the IA task produced short-term memory, lasting no longer than $15 \mathrm{~min}$ [Moncada and Viola (2007), their Fig. 1a (http:// www.jneurosci.org/cgi/content/full/27/28/ 7476/F1)]. However, when a 5 min session of spatial novelty was given just before the IA task, the short-term memory was converted into a persistent memory lasting $24 \mathrm{~h}$ [Moncada and Viola (2007), their Fig. $1 b$ (http://www.jneurosci.org/ cgi/content/full/27/28/7476/F1)]. Similarly, when the spatial novelty was given after IA training, memory was also extended [Moncada and Viola (2007), their Fig. $4 a$ (http://www.jneurosci.org/cgi/ content/full/27/28/7476/F4)]. These results resembled the symmetry of the seminal electrophysiological experiments, where a strong tetanus applied either before or after weak tetanization in a different pathway resulted in late-LTP in the weakly stimulated pathway (Frey and Morris, 1997, 1998). Like the previous data, Moncada and Viola defined a restricted temporal window within which coincidence of the two behavioral experiences leads to long-term memory for the weak IA training.

Originally, Frey and Morris (1997, 1998) proposed that weak stimulation established a "tag" in certain synapses. This tag would then capture newly synthesized plasticity proteins that were required for a more persistent potentiation and that were provided by the strong stimulation. Extending the model to the behavioral 
data in Moncada and Viola (2007), certain synapses, tagged by the weak IA training, would capture the plasticity proteins provided by spatial novelty. To explore this possibility, the authors blocked new protein synthesis after the open field session, but before IA training. Stereotaxic infusions of the protein synthesis inhibitor anisomycin into CA1 immediately after the open field session disrupted long-term memory for the weak IA training performed $1 \mathrm{~h}$ after the first task [Moncada and Viola (2007), their Fig. $3 a$ (left) (http://www.jneurosci.org/ cgi/content/full/27/28/7476/F3)]. However, anisomycin had no effect on strong IA training [Moncada and Viola (2007), their Fig. 3a (right) (http://www.jneurosci.org/ cgi/content/full/27/28/7476/F3)], indicating that it did not affect IA memory consolidation. Furthermore, IA long-term memory was impaired by anisomycin infusions immediately before training, and it was rescued when preceded by an open field session [Moncada and Viola (2007), their Fig. $3 b$ (http://www.jneurosci.org/ cgi/content/full/27/28/7476/F3)]. Together, these results suggest that new protein synthesis triggered by spatial novelty was necessary and sufficient to drive memory consolidation for IA training. Additionally, because anisomycin acts intracellularly, the observed effects indicate that both behavioral experiences converge onto common cellular substrates. As reported for CA1 responding neurons in animals exposed to two spatial contexts (Vazdarjanova and Guzowski, 2004), the extent of overlapping between open field and IA within CA1 seemed not to be complete, because the memory rescue was only partial [compare open field rescued with vehicle injected in Moncada and Viola (2007), their Fig. $3 b$ (http://www. jneurosci.org/cgi/content/full/27/28/7476/ F3)]. However, both behavioral tasks very unlikely activated the very same synapses within the neurons onto which they converge. This scenario is reminiscent of the two-pathway stimulation experiments, in which two electrodes stimulated different synaptic inputs to the same neuron. Moreover, from a temporal point of view, the stimuli presented here were applied too far in time to be integrated by means of the coincidence detection mechanism of the NMDA receptor. Additional mechanisms are required to extend the temporal frame for late associativity (Reymann and Frey, 2007). Given that the behavioral interaction required new protein synthesis and seemed to involve a heterosynaptic phenomenon,
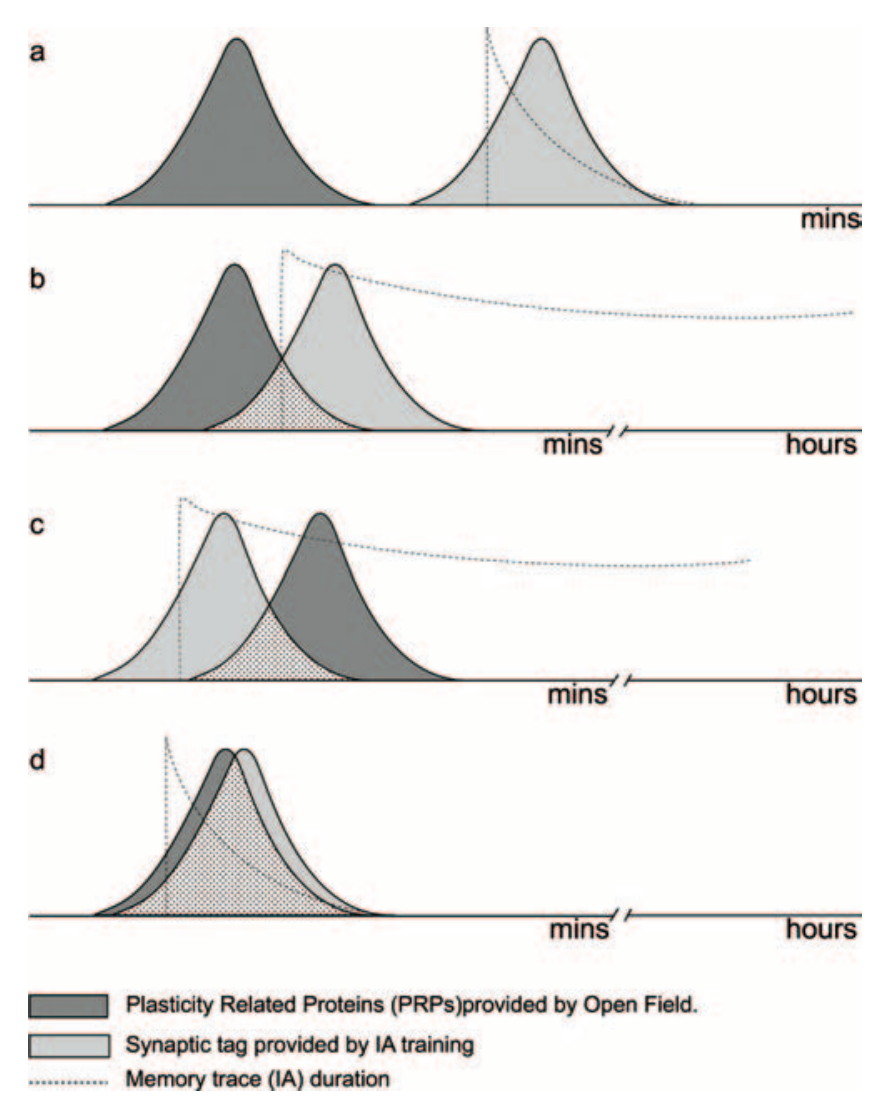

Figure 1. Schematic summary of the behavioral tagging results provided by Moncada and Viola (2007). The magnitude and duration of the variety of phenomena involved are schematically depicted: the IA memory trace and the putative molecular requirements occurring within the same CA1 neurons activated by both spatial novelty and IA training. These neurons would drive the consolidation of IA memory induced by a weak training through a heterosynaptic plasticity process. A set of synapses specifically tagged by the weak IA training-induced neuronal activity would capture the newly synthesized PRPs provided by the spatial novelty stimulation. $\boldsymbol{a}$, As expected, weak IA training (light gray) led to shortterm memory (dotted line), and previous exposure to open field (dark gray) did not affect the IA memory duration when both tasks were spaced by at least $120 \mathrm{~min}$. A similar result was observed when the open field was performed after the weak IA training (data not shown). b, c, Conversely, previous (b) or posttraining (c) open-field exposure promoted IA long-term memory when both situations were sufficiently close to each other. $\boldsymbol{d}$, However, novel environment exploration either just before or immediately after training did not result in a switch from short- to long-term IA memory. Adapted from Morris (2006).

the synaptic tagging and capture model may be a suitable explanation (Fig. 1).

A number of parallels emerge from the comparison with previous studies. In addition to the symmetry and the existence of a restricted temporal window, the dopamine neurotransmitter system has been involved in both kind of results (Sajikumar and Frey, 2004). Moreover, the IA LTM rescue by spatial novelty mimics the paradoxical induction of LTP in presence of anisomycin described in the seminal experiments of Frey and Morris (1997, 1998).

It is noticeable, however, that a number of issues need to be addressed. First, the original hypothesis itself remains undemonstrated, because no direct observation of a tag-mediated capture of plasticity factors has been reported. Imaging of subcellular targeting of activity synthesized molecules or biochemical evidences of a molecular interaction required for synaptic capture would provide significant insight. Second, there are some important discrepancies between behavioral and electrophysiological tagging results. For instance, the switch from short- to longterm memory was not achieved when the spatial novelty was applied $30 \mathrm{~min}$ before [Moncada and Viola (2007), their Fig. $1 b$ (http: // www.jneurosci.org / cgi/content / full/27/28/7476/F1)] or immediately after [Moncada and Viola (2007), their Fig. 4a (http://www.jneurosci.org/ cgi/ content/ full / 27/28/7476/F4)] the weak IA training. Such exceptions within the permissive time window were not observed in hippocampal slices during early-to-late LTP conversion.

In summary, the results provided by Moncada and Viola (2007) share several phenomenological properties with those 
in two-pathway stimulation experiments. It is possible that the observed discrepancies reflect minor differences that can be fit within the original model, although they might also reflect unrelated phenomena. All these questions remain to be solved. In the meantime, the results by Moncada and Viola (2007) suggest that synaptic tagging and synaptic capture could underlie long-term memory formation and might provide an explanatory mechanism for the recall of irrelevant events that happened around outstanding events.

\section{References}

Bliss TV, Collingridge GL (1993) A synaptic model of memory: long-term potentiation in the hippocampus. Nature 361:31-39.
Frey U, Morris RG (1997) Synaptic tagging and long-term potentiation. Nature 385:533-536.

Frey U, Morris RG (1998) Weak before strong: dissociating synaptic tagging and plasticityfactor accounts of late-LTP. Neuropharmacology 37:545-552.

Gruart A, Muñoz MD, Delgado-Garcia JM (2006) Involvement of the CA3-CA1 synapse in the acquisition of associative learning in behaving mice. J Neurosci 26:1077-1087.

Moncada D, Viola H (2007) Induction of longterm memory by exposure to novelty requires protein synthesis: evidence for a behavioral tagging. J Neurosci 27:7476-7481.

Morris RG (2006) Elements of a neurobiological theory of hippocampal function: the role of synaptic plasticity, synaptic tagging and schemas. Eur J Neurosci 23:2829-2846.

Reymann KG, Frey JU (2007) The late maintenance of hippocampal LTP: requirements, phases, 'synaptic tagging', 'late-associativity' and implications. Neuropharmacology 52:24-40.

Sajikumar S, Frey JU (2004) Late-associativity, synaptic tagging, and the role of dopamine during LTP and LTD. Neurobiol Learn Mem 82:12-25.

Vazdarjanova A, Guzowski JF (2004) Differences in hippocampal neuronal population responses to modifications of an environmental context: evidence for distinct, yet complementary, functions of CA3 and CA1 ensembles. J Neurosci 24:6489-6496.

Vianna MR, Alonso M, Viola H, Quevedo J, de PF, Furman M, de Stein ML, Medina JH, Izquierdo I (2000) Role of hippocampal signaling pathways in long-term memory formation of a nonassociative learning task in the rat. Learn Mem 7:333-340.

Whitlock JR, Heynen AJ, Shuler MG, Bear MF (2006) Learning induces long-term potentiation in the hippocampus. Science 313:1093-1097. 